\title{
Desain Kondominium Terpapar sebagai Stimulasi Kecerdasan
}

\author{
Dian Qurrota A'yun dan I Gusti Ngurah Antaryama \\ Departemen Arsitektur, Fakultas Arsitektur, Desain dan Perencanaan,Institut Teknologi Sepuluh Nopember (ITS) \\ e-mail: antaryama@arch.its.ac.id
}

\begin{abstract}
Abstrak - Intelektual manusia merupakan sebuah investasi dalam membangun dunia. Setiap program peningkatan intelektual dapat menghasilkan sumber daya manusia yang lebih berkualitas. Manusia merupakan makhluk yang selalu berfikir dengan otak sepanjang hayatnya. Otak terdiri dari kompleksitas sistem saraf yang mengandung lebih dari seratus miliar neuron dan masing - masing neuron memiliki rata-rata 7000 koneksi sinaptik dan sekitar $\mathbf{5 0 0}$ triliun sinapsis yang terkoneksi melalui medium indra. Unsur dasar intelektual kognitif $50 \%$ pada otak merupakan indrawi visual, yang kemudian indrawi ini mengarah kepada spesifikasi visual konfigurasi terpapar. Konfigurasi ini mempunyai parameter dalam mendesain yaitu tinjauan spasial dan pencahayaan alami pada Bangunan. Hal tersebut merespons kebutuhan fungsional hunian generasi Homelander yang lahir pada tahun 2005 keatas mempunyai kecenderungan sering menghabiskan waktu dirumah dan ketergantungan dengan alat digital yang menimbulkan dampak negatif, mempengaruhi daya pikir dan penurunan intelektual kognitif seiring perkembangan syaraf pada otak. Proyek ini ditunjang dengan Metode Desain diantaranya metode Research, Interweaving, Repetition dan Rotation yang secara efektif diterapkan pada elemen desain Kondominium. Terapan zoning acak menghasilkan setiap unit dengan luasan ekonomi yang berbeda memanifestasikan kualitas yang relatif sama. Denah menukik menciptakan sudut binar dan pandangan kemeruangan luar yang spektakuler. Podium berkontur kompleks bersamaan dengan gubahan massa jamak memicu masyarakat mengaktivasi sel-sel sulkus lingual pada otaknya. Fasad kaca up down left right view mewujudkan penghuni dapat mengeksplor pandangan ke segala arah dengan jarak pandang lebih luas, serta instalasi hollow light pipe dan atrium sebagai pencahaayan alami area ruang dan koridor bentang lebar yang tidak tersinari secara maksimal. Batasan kekuatan struktur pun menjadi sesuatu yang terkeksplor guna menunjang capaian yang ada. Setiap elemen desain diputuskan berdasarkan parameter terpapar yang secara tegas merealisasikan keintegrasian secara menyeluruh.
\end{abstract}

Kata Kunci-Fenomenologi Intelektual, Kognitif Spasial, Pencahayaan Alami, Sulkus Lingual.

\section{PENDAHULUAN}

$\mathrm{S}$ EJAK jaman dahulu, penggabungan 2 sub-ilmu atau lebih telah dilakukan ratusan abad yang lalu oleh ilmuan dunia. Hal ini menciptakan berbagai solusi dalam penyelesaian masalah yang ada, melahirkan terapan desain Kondominium Konfigurasi Terpapar (Gambar 1, 4 dan 7). Neuroscience dan Arsitektur merupakan penggabungan 2 sub-ilmu yang lahir cukup dini pada abad ke21 ini, yaitu tepatnya pada tahun 2013 silam oleh John P Eberhard dan dijelaskan secara detail dalam bukunya, Brain Landscape. Penggabungan 2 sub-ilmu ini ditunjang oleh ilmuan Neuroscience Michael Arbib sebagai

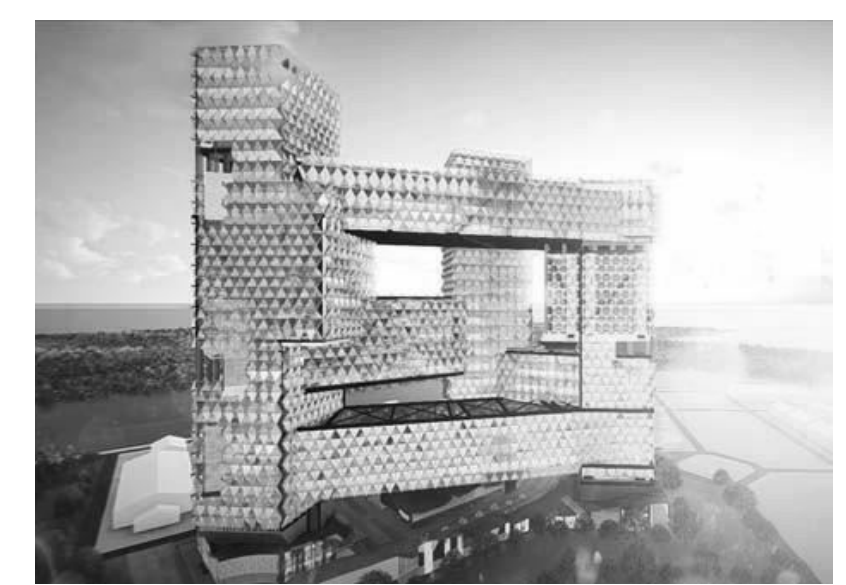

Gambar 1. Perspektif Kondominium Sisi Barat Daya



Gambar 2. Fasad Kaca Spasial dan Pencahayaan Alami

ahli saraf pada otak dan Professor Harry yang mendapat gelar nya dalam ranah arsitektur. Ilmu ini kemudian di tulis kembali dalam buku Neuroscience and Architecture oleh Juhanni Pallasmaa. Neuroscience merupakan perkembangan ilmu biologi yang bersumber dari ilmu kedokteran, yang khususnya mempelajari sistem sel saraf pada otak manusia ilmu Neuroscience terus berkembang hingga pemahaman yang cukup dalam tentang kinerja pada otak manusia, yang secara eksplisit ditetapkan sebuah penelitian bahwa kompleksitas suatu pandangan/kemeruangan pandangan spasial dan pencahayaan alami dapat menstimulus kinerja pada otak menciptakan berbagai elemen desain Kondominium (Gambar 2, 3, 5 dan 6). Sedangkan Arsitektur merupakan ilmu merancang bangunan dan lansekap dalam lingkup makro maupun mikro. Maka dapat dipahami, Arsitektur dengan topik Neuroscience merupakan desain bangunan dan lansekap yang bertujuan untuk pencapaian aktivasi sel-sel saraf pada otak manusia. 


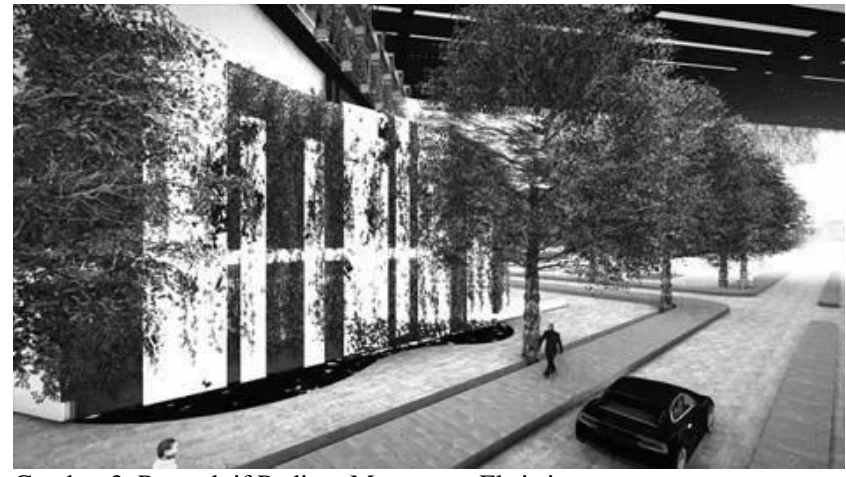

Gambar 3. Perspektif Podium Merespons Eksisting.

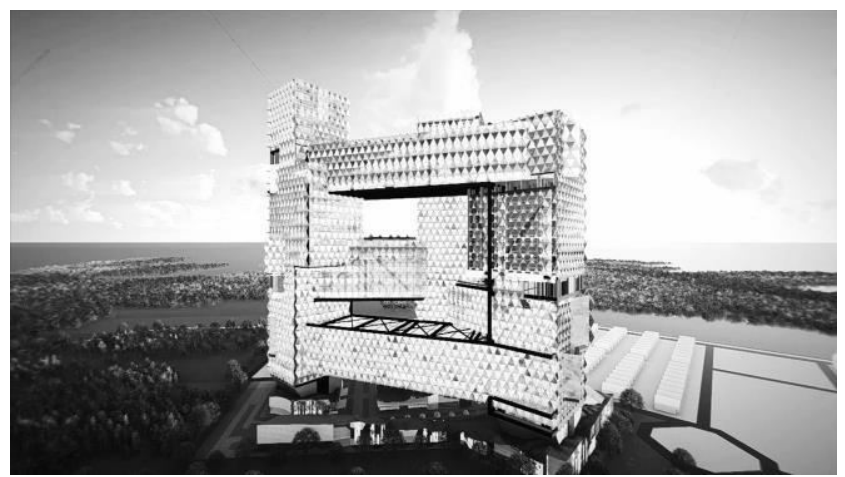

Gambar 4. Perspektif Kondominium Sisi Tenggara.

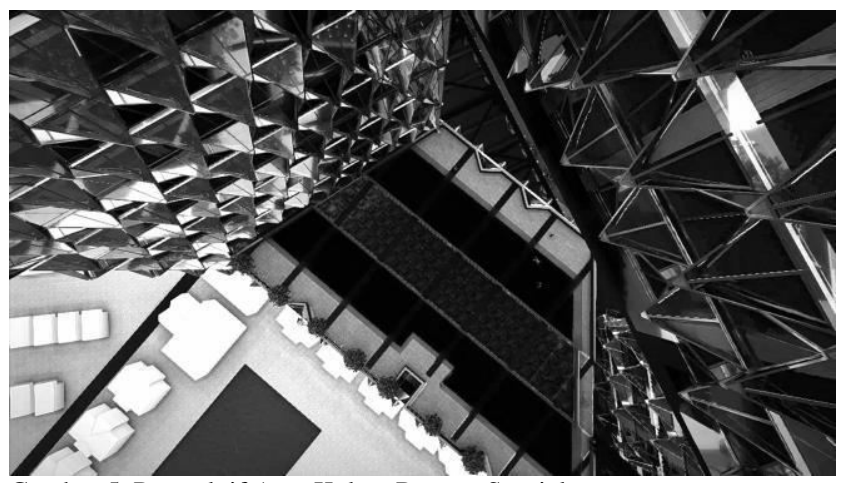

Gambar 5. Perspektif Area Kolam Renang Spasial.

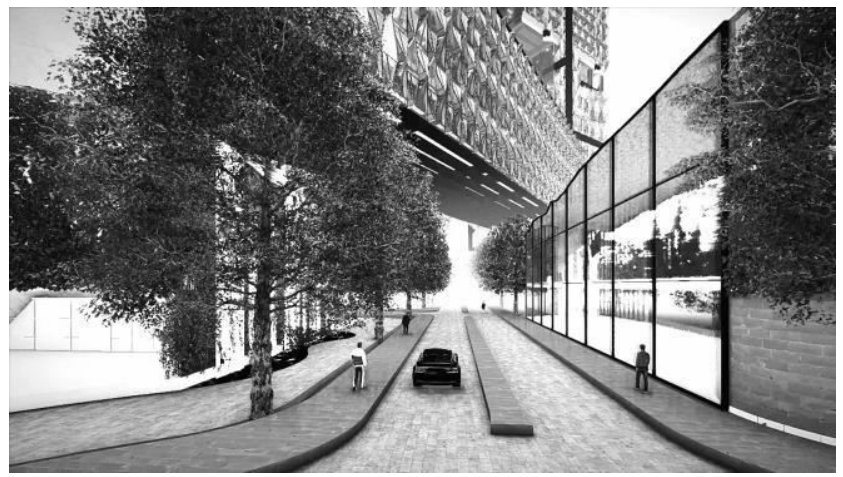

Gambar 6. Perspektif Fenomena Podium.

\section{A. Isu dan Konteks Desain}

Terdapat 25 klasifikasi generasi berdasarkan karakternya dalam perjalanan sejarah manusia [4]. Klasifikasi generasi terakhir yang telah di patenkan merupakan generasi yang lahir pada tahun 2005 keatas. Generasi ini sering disebut juga

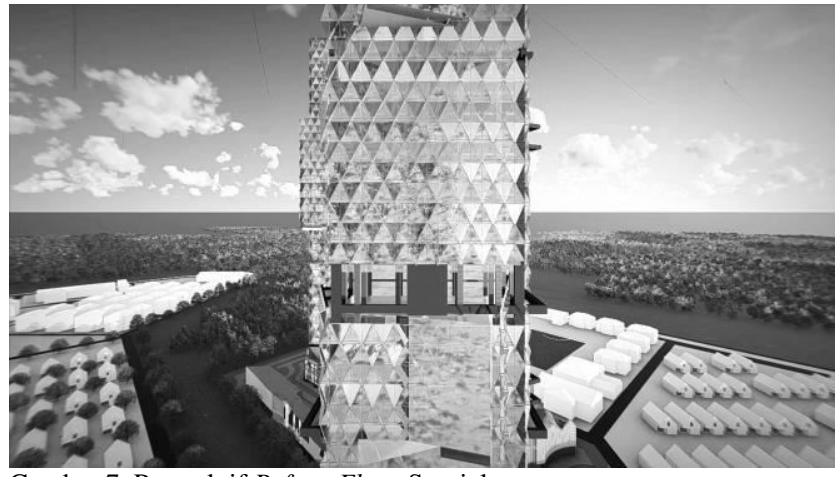

Gambar 7. Perspektif Refuge Floor Spasial.

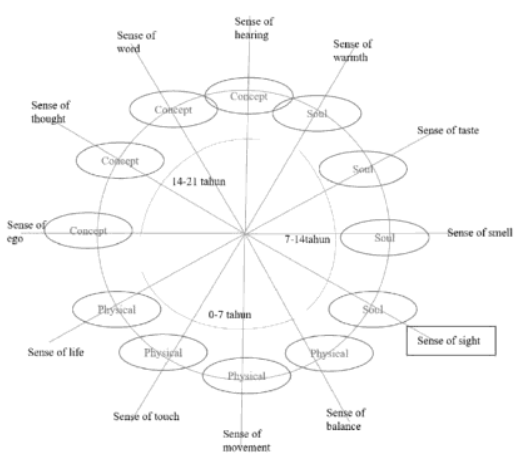

Gambar 8. Skema Pembagian Indra oleh Rudolf Joseph Steiner [1].


Gambar 9. Perbedaan Hasil Area Sulkus Lingual pada Otak [2].



Gambar 10. Volex Aktif Pada PPA di Sulkus Lingual Otak [3].

dengan generasi setelah generasi $\mathrm{Z}$ oleh masyarakat dunia. Generasi Homelander cenderung sering menghabiskan waktu di rumah dan sangat ketergantungan dengan alat digital [4]. Alat digital atau gadget mempunyai dampak negatif yaitu salah satunya jika terlalu sering menggunakan alat digital dapat mempengaruhi daya pikir yang sejalan dengan pertumbuhan 


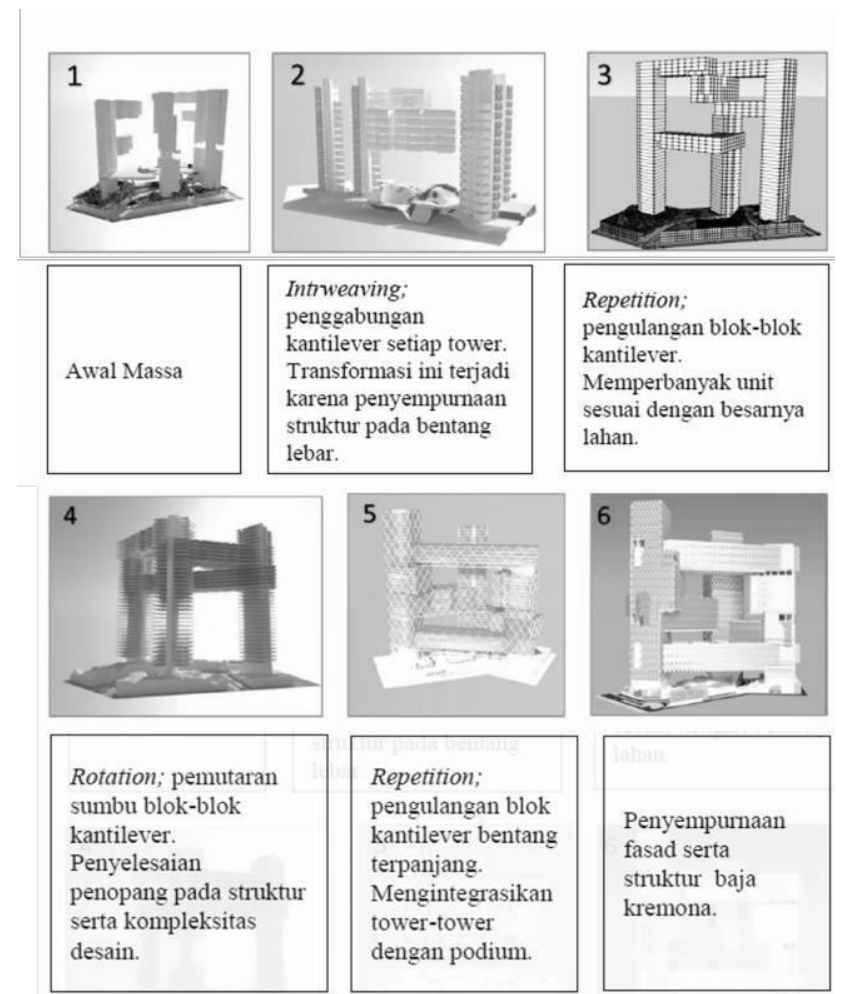

Gambar 11. Metode dan Proses Mendesain.


Gambar 12. Konsep Zoning Unit Acak

syaraf otak, hal ini dapat mengakibatkan penurunan proses berfikir, pola pikir dan tingkat paham akan kepekaan seseorang [5]. Penurunan perkembangan ini dikenal sebagai penurunan perkembangan kognitif [6].

\section{B. Permasalahan Generasi Homelander}

Generasi Homelander dengan dampak negatif ketergantungan alat digital serta kecenderungan pada karakter generasi ini yaitu sering menghabiskan waktu di rumah menimbulkan beberapa faktor penurunan intelektual kognitif.

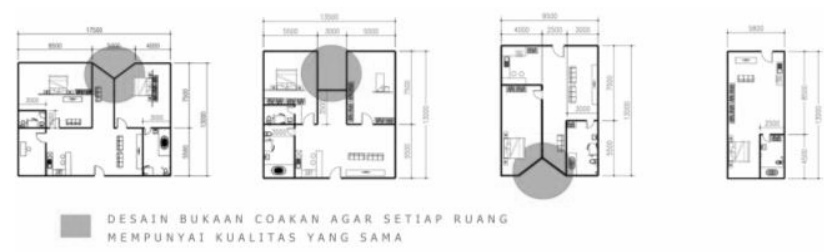

Gambar 13. Konsep Denah Menukik.

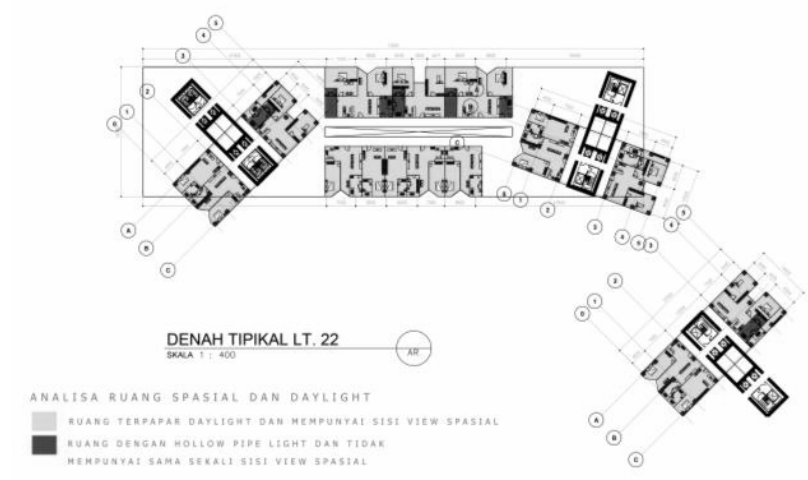

Gambar 14. Analisa Denah Tipikal Spasial dan Pencahayaan Alami/ Perbandingan Area Terpapar dan Tidak.

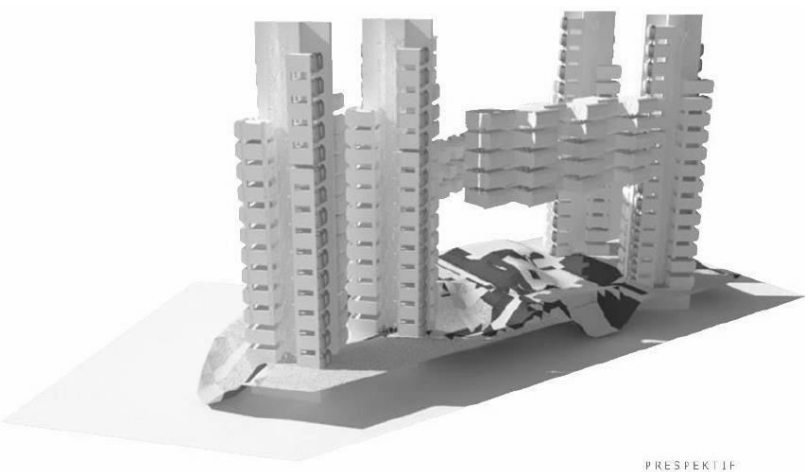

Gambar 15. Konsep Podium Merespon Eksisting.

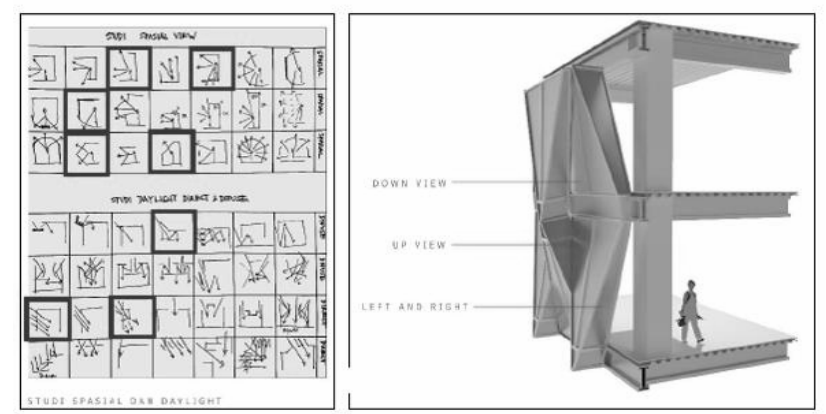

Gambar 16. Konsep Fasad Kaca Spasial

Hal ini dapat memicu suatu gagasan hunian yang dapat meningkatkan kemampuan intelektual kongnitif pada manusia.

\section{Kriteria Desain}

Kriteria Desain merupakan acuan dalam membuat konsep desain. Kriteria desain dalam Proyek Kondominium ini adalah spasial dan pencahayaan alami. Keduanya dipakai sebagai acuan dalam mendesain setiap elemen yang dihadirkan dalam konsep. 




Gambar 18. Konsep Down Spot View.

\section{Pendekatan Desain Neurophenomenology}

Manusia merupakan makhluk yang selalu berfikir dengan otaknya sepanjang hayatnya. Saraf merupakan serat-serat yang menghubungkan organ-organ tubuh dengan sistem saraf pusat, yakni otak dan sumsum tulang belakang. Otak terdiri dari beberapa bagian yang mempunyai fungsi masing-masing, bagian-bagian tersebut saling Mendominasi dan dan mempengaruhi kondisi dan kemampuan seseorang. Otak terdiri dari kompleksitas sistem saraf yang mengandung lebih dari seratus miliar neuron dan masing - masing neuron memiliki rata-rata 7000 koneksi sinaptik dan sekitar 500 triliun sinapsis [3]. Hal tersebut mempengaruhi Arsitek dalam proses merancang bangunan. Kompleksitas dan plastisitas otak manusia menekankan sifat bawaan multi-sensori dalam pengalaman arsitektur yang menimbulkan eksplorasi desain [3]. Indra yang terdapat pada manusia merupakan penghubung antara batasan luar tubuh dengan organ dalam salah satunya syaraf-syaraf yang terdapat pada otak. Indra manusia berperan menerima dan memproses informasi yang kemudian disalurkanoleh sistem sensori lainnya [2]. Neurophenomenology merupakan pendekatan yang harmonis dalam penanganan permasalahan generasi Homelander, aktivitas indra ini mengarah kepada syaraf yang berkerja untuk peningkatan pemahaman kognitif pada otak.

\section{E. Teori}

Teori Indra Visual merupakan unsur dasar intelektual kognitif 50\% pada otak membentuk pengalaman individu pada manusia menggunakan indrawi visual, yang kemudian indrawi ini mengarah kepada spesifikasi visual konfigurasi terpapar. Pembagian indra pada skema Gambar 8 merupakan penjelasan segmentasi umur dalam pemahaman indra oleh Steiner yang dikelompokan menjadi 3 rentang umur, dan Sense of Sight / Indra Visual merupakan indra yang dapat dipahami oleh segala jenis umur. Hal tersebut membuat manusia yang tinggal di hunian Kondominium menangkap setiap elemen desain dan mentransmisikannya kepada otak dengan mudah. Teori kognisi spasial terhadap otak lebih tepatnya Parahippocampal Place Area (PPA) merupakan sub-wilayah parahippocampal yang terletak di korteks temporo-oksipital inferior. PPA tersebut mempunyai peran penting dalam pengkodean dan pengenalan lingkungan (bukan wajah) [7]. Dalam serangkaian percobaan menunjukan bahwa voxel (Gambar 9) pada PPA merespons lebih kuat terhadap ruang dan tempat dari pada rangsangan visual lainnya, yaitu secara signifikan lebih aktif bila subjek melihat pemandangan yang kompleks, seperti ruangan, lansekap, pemandangan, daripada ketika melihat foto



Gambar 19. Konsep Hollow Light Pipe

benda, wajah, dan jenis rangsangan visual lainnya. Yang artinya aktivasi otak manusia akan mengalami kenaikan pemahaman (IQ) ketika melihat lansekap dibanding benda tunggal.

Sedangkan teori kognisi pencahayaan alami terhadap otak (Gambar 10). Dalam sebuah penelitian ditemukan bahwa anak anak di ruang kelas yang diterangi cahaya alami mencapai nilai tes yang lebih tinggi dibanding anak-anak diruang kelas yang diterangi cahaya buatan [8]. Hal ini mempengaruhi arsitektur yang dapat mendukung kemampuan intelektual kognitif manusia. Cahaya, bayangan dan pantulan mempunyai peran penting. dalam meningkatkan rangsang sensitivity suprachiasmatic $(\mathrm{SCN})$, mempengaruhi kewaspadaan manusia [8].

\section{METODE DESAIN}

\section{A. Metoda}

Pengambilan metode dalam proyek ini yaitu proses pengumpulan informasi penelitian yang sudah menghasilkan uji coba explorasi formal elemen desain yang bertujuan menjadi acuan dalam mengkonsepkan proyek sehingga dapat menyelesaikan masalah yang ada. Metode ini disebut dengan metode desain research yang dipakai dalam proses penyusunan proposal studi.

Metoda desain dalam proses mendapatkan massa suatu bangunan merupakan cara kerja untuk dapat memahami dan mencapai objek desain rancang. Metoda-metoda yang dipakai ialah Interweaving, Rotation, Repetiton. Interweaving merupakan metoda yang sering disebut dengan menjalin atau menggabungkan satu benda dengan benda yang lainnya. Metoda Rotasi merupakan metoda desain memutar sumbu tertentu pada suatu benda. Sedangkan Metoda Repetition merupakan Metoda Desain pengulangan. Kumpulan Metoda ini dipakai sepenuhnya dalam proses desain massa Kondominium (Gambar 11).

\section{B. Kerangka Kerja}

Kerangka kerja dalam proyek ini memakai kerangka kerja Concept-Based Framework dari buku Revealing Architecture Design: Methods, Framework and Tools. Framework ini digunakan sebagai pedoman kerangka kerja dalam proses mendesain karena setiap elemen desain pada proyek ini mengarah pada konsep seutuhnya, yang ditinjau dari proyek desain Kondominium berdasarkan bukti desain pencahayaan alami dan penanganan spasial secara visual dapat menyelesaikan masalah intelektual kognitif dalam isu generasi 


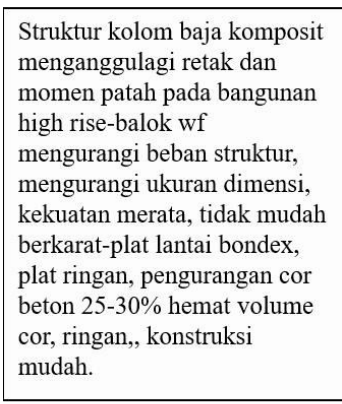

Struktur baja Cremona, termasuk stuktur yang memiliki kualitas yang sangat baik. Struktur ini biasa menopang berton beban kendaraan dalam sturktur jembatan. Kekuatan yang sangat besar, daya

elastisitasnya dapat diketahui, daya tahan sangat lama, dapat mengurangi beban geser dengan mencekram core.

Struktur podium, plat beton cor mengikuti tinggi turunnya kontur, mengurangi beban tanah pada atap kontur tanah.

Gambar 20. Konsep Struktur

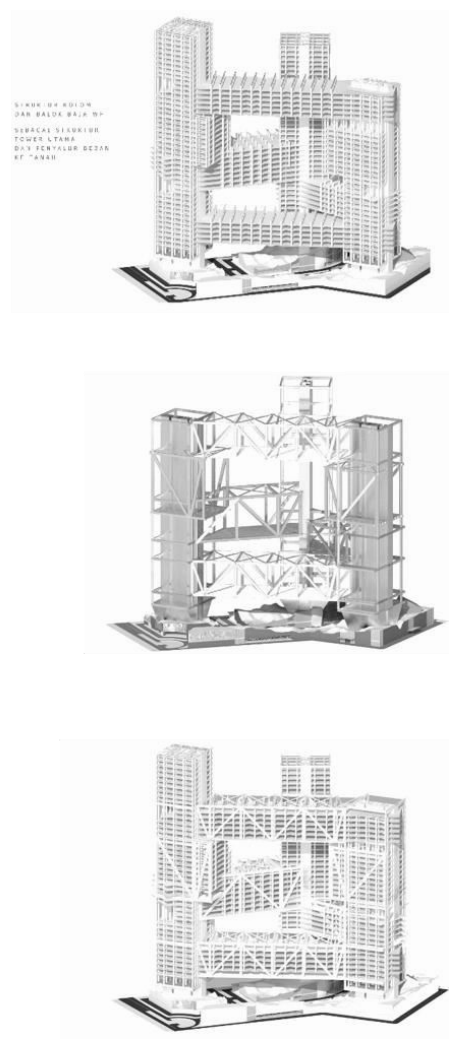

Homelander. Selain berdasarkan Concept-Based Framework Proyek ini membuat desain antara lain konsep podium berdasarkan kondisi eksisting/sekitar yang artinya mencakup Forces-Based Framework, tetapi tetap sebagian besar sekitar $3 / 4$ desain berpacu pada acuan konsep yang ada.

\section{KONSEP DESAIN}

\section{A. Eksplorasi Formal}

Elemen desain pada proyek ini berpacu pada hasil riset Spasial dan Pencahayaan alami dapat meningkatkan aktivasi pada otak manusia secara efektif diterapkan pada elemen desain antara lain; zoning, denah, podium, fasad dan gubahan massa merupakan elemen desain yang terfokus pada parameter tersebut.

Pemilihan opsi zoning agar setiap unit mempunyai kualitas yang sama tanpa memandang ekonomi maka Proyek Kondominium ini memakai Opsi kedua (Gambar 12); Zoning ditaruh secara acak pada massa horizontal maupun vertikal. Zoning ini merupakan salah satu solusi agar setiap hunian mendapatkan cahaya pantul, bias maupun difus dan mendapatkan fenomena spasial yang sama.

Peletakan denah menukik (Gambar 13) dan konfigurasi setiap ruangan mempengaruhi desain proyek kondominium. Setiap Ruangan pada setiap unit didesain mempunyai pemandangan kearah luar, kecuali ruangan yang sifatnya tertutup; toilet pada unit A dan B yang tidak mendapatkan pemandangan dikarenakan estimasi padatnya ruangan lain yang lebih prioritaskan untuk mendapatkan area spasial dan pencahayaan alami. Berikut salah satu contoh denah keseluruhan pada lantai 22 (Gambar 14);
Pada tersebut diatas dijelaskan bahwa konfigurasi spasial dan pencahayaan alami pada setiap ruang unit Kondominium (tosca) perbandingannya lebih besar dibanding ruang yang tidak mendapatkan spasial dan pencahayaan alami(merah) dengan perbandingan 3:1.

Podium merupakan bagian transisi antara zona privat dan publik. Podium dalam Proyek Kondominium ini dirancang untuk merespon dan kondisi eksisting (sekitar). Dimana tidak hanya penghuni Kondominium yang dapat mengaktivasi elemen saraf sulkus lingual pada otak tetapi warga sekitar pun dapat mengaktivasinya dengan cara melihat pemandangan spasial pada dinding podium yang tertutupi oleh lansekap diantaranya (Gambar 15, 3 dan 6); tanaman rambat dan air terjun buatan yang menyambung dari atap podium yang berkontur.

Fasad dalam Proyek Kondominium ini di olah mengikuti studi spasial dan pencahayaan alami yaitu berupa elemen terpapar; kaca. Bentuk dan orientasi kaca didesain berdasarkan efektifitas jarak pandang terbanyak dan terluas, menghasilkan kaca down, up dan left \& right view (Gambar 16 dan 2). Dimana Penghuni dapat mengakses pengelihatan secara maksimal. Bentuk ini juga mempengaruhi banyaknya cahaya pantul dan bias membuat setiap ruangan tersinari oleh cahaya alami.

Gubahan massa merupakan suatu proses dalam merancang Proyek Kondominium ini. Awal massa berupa 3 tower utama berbentuk huruf $F$ (Gambar 11.1) tower berbentuk $F$ ini bertujuan agar penghuni mempunyai fenomena pengelihatan yang memenuhi standar diagram explorasi arah. Dikarenakan bentukan ini mempunyai kelemahan pada struktur maka tower yang mengantung disatukan antar tower lainnya (Gambar 11.2). Percobaan silang tower horizontal (Gambar 11.3) telah menghadirkan permasalahan struktur seperti pada percobaan pada Gambar 11.3 maka terbentuklah Gambar 11.4. Explorasi silang masih berlanjut dan pada akhirnya menciptakan Gambar 11.5; tower horizontal terpanjang diletakkan paling bawah hingga hampir menyentuh podium agar bangunan menjadi satu kesatuan antara podium dan tower yang menjulang tinggi, pada Gambar 11.6 yaitu finishing gubahan massa mempunyai tower penumpu struktur kremona tower horizontal bentang terpanjang $(180 \mathrm{~m})$. Hasil akhir massa terdapat 3 Tower Vertikal dan 3 Tower Horizontal. Masing masing tower dengan ketinggian 401t-45lt dan 501t (Tower Vertikal) dan 5lt dengan bentang $180 \mathrm{~m}$, 6lt dengan bentang $180 \mathrm{~m}, 8 \mathrm{lt}$ dfengan bentang 129m, 6 lt dengan bentang $101 \mathrm{~m}$. Atrium merupakan ruang terbuka pada proyek Kondominium. Atrium ini berfungsi sebagai masuknya cahaya yang bermaterialkan kaca (Gambar 17). Pencahayaan ini berfungsi sebagai penerangan alami pada koridor/lorong di setiap unit horizontal. Selain itu atrium ini mencapai diagram spasial up and down view pada interior bangunan.

Down spot view merupakan area dimana penguni dapat menjejakkan kakinya pada kaca setebal $1.5 \mathrm{~m}$ dengan bentuk lingkar, kaca ini tembus pandang down spot view ke arah podium yang mempunyai atap kontur (Gambar 18). Pencapaian desain ini hanya terletak pada tower horizontal bentang $180 \mathrm{~m}$ dimana terdapat ruang transisi antar tower bentang $180 \mathrm{~m}$ dengan tower vertikal tengah. Pemandangan down spot view ini akan mempunyai pemandangan yang spektakular berada pada ketinggian tertentu dengan berdiri 
diatas kaca lingkar.

Pencahayaan alami merupakan salah satu dari 2 kriteria desain. Pada kebanyakan apartemen, kondominium, maupun hunian lainnya bukaan pada dinding mempunyai skala yang sangat minim, bahkan hanya 1 atau 2 ruangan yang terpapar oleh pencahayaan alami. Pada proyek Kondominium ini setiap ruangan mempunyai kualitas penerangan alami secara maksimal dengan cara memantulkan cahaya pada pipa hollow yang ditanamkan dalam plafon (Gambar 19). Salah satu sudut plafon diberi bukaan sehingga cahaya dapat diteruskan ke ruangan yang dituju.

\section{B. Eksplorasi Teknis Struktur}

Arsitektur dan struktur, mempunyai korelasi yang cukup erat. Ketika konsep di terapkan dalam sebuah desain maka struktur pun mengikutinya, ada beberapa tahapan dimana suatu struktur mempunyai beberapa batasan kekuatan, yang memicu elemen struktur menjadi tereksplor, guna melengkapi konsep dan menunjang konsep secara utuh (Gambar 20).

\section{KESIMPULAN}

Kondominium dengan konsep konfigurasi terpapar hadir sebagai solusi bagi generasi Homelander yang mengalami penurunan intelektual. Setiap keputusan elemen desain pada proyek ini dipertimbangkan berdasarkan acuan hasil riset spasial dan pencahayaan alami melalui indrawi visual, yang secara efektif dapat meningkatkan aktivasi sel-sel saraf pada otak manusia. Bangunan Kondominium ini mempunyai 869 unit dengan luas tanah 2,2 hektar, setiap unitnya mempunyai kualitas spasial yang spektakuler, dan pencahayaan alami maksimum, dengan terapan desain kaca prismatik yang memungkinkan penghuni melihat segala ke segala arah dengan jarak pandang lebih jauh, sedangkan denah menukik membuat area non spasial menjadi terbuka serta hollow pipe yang memudahkan cahaya alami memantul ke area yang tidak tersinari. Olahan elemen desain membuat struktur kantilever menjadi suatu elemen yang dapat di eksplor lebih dalam, yang menunjang konsep dengan berbagai keuntungan kualitas material. Podium air terjun dapat membuat warga dapat mengaktivasi sulkus lingual pada otaknya dan atap kontur yang ditumbuhi berbagai tanaman cukup kompleks membuat penghuni dalam unit mendapatkan visualisasi area down view maksimum. Setiap elemen desain diputuskan berdasarkan parameter terpapar menjadi satu kesatuan utuh yang dapat menjawab permasalahan generasi Homelander.

\section{DAFTAR PUSTAKA}

[1] R. Steiner, 12 Sense, The Boundaries of Natural Science. London: Rudolf Steiner Press, 1920.

[2] J. Pallasmaa, The Eyes of The Skin: Architecture and Sense. Chichester: Wiley, 1996.

[3] J. Pallasmaa, Mallgrave, H. Francis., and M. Arbib, Architecture and Neuroscience. Tapio Wirkkala-Rut Bryk Foundation, 2013.

[4] Life Course Associates, "Generations in History," California, 2010.

[5] S. M. Diana, "Peranan Cognitive Neuroscience Dalam Dunia Pendidikan," Jakarta, 2011.

[6] P. Sarlito, CBS New York. CBS New York, 1991.

[7] Epstein and Kanwisher, "Departement of Brain and Cognitive Sciences," Cambridge, 1999.

[8] J. P. Eberhard, Brain Landscape, The Coexistance of Neuroscience and Architecture. California: Oxford University Press, 2009. 